\title{
Modelling of a Cervical Plate and Human Cervical Section C3 - C5 under Compression Loading Conditions Using the Finite Element Method
}

\author{
J.A. Beltrán-Fernández ${ }^{1 \mathrm{a}}$, L.H.Hernández-Gómez ${ }^{2 \mathrm{~b}}$, R.G. Rodríguez-Cañizo ${ }^{3 \mathrm{c}}$, E.A. \\ Merchán-Cruz ${ }^{3 c}$, G. Urriolagoitia-Calderón ${ }^{2}, A$. González-Rebatú ${ }^{4}$, \\ M. Dufoo-Olvera ${ }^{5}$ and G. Urriolagoitia-Sosa ${ }^{3 c}$
}
${ }^{1}$ Escuela Superior de Ingeniería Mecánica y Eléctrica (ESIME) Unidad Culhuacán, Av. Santa Ana No. 1000 Col. San Francisco Culhuacán, 04430, México.
${ }^{2}$ Escuela Superior de Ingeniería Mecánica y Eléctrica (ESIME) Unidad Zacatenco, Edificio 5, 3er Piso, 07738, D.F., México.
${ }^{3}$ Escuela Superior de Ingeniería Mecánica y Eléctrica (ESIME) Unidad Azcapotzalco, Av. Granjas No. 682 Col. Sta. Catarina, 02550, México.
${ }^{4}$ Hospital Regional ISSSTE 1ํ de Octubre, Av. Instituto Politécnico Nacional. Núm. 1669, Col. Magdalena de las Salinas, 07760, México.
${ }^{5}$ Hospital de Urgencias La Villa, Av. San Juan de Aragón, 07760, México.

ajbeltran@ipn.mx, 'Pluishector56@hotmail.com, 'rorodriguez@ipn.mx, deamerchan@ipn.mx

Keywords: Stresses, Cervical Plate, Vertebrae, bone graft, Corporectomy.

\begin{abstract}
This paper presents the modelling of the effects due to load conditions on the cervical section defined between $\mathrm{C} 3$ and $\mathrm{C} 5$ after a cervical plate implant is used to transfer the compression loads from $\mathrm{C} 3$ to $\mathrm{C} 5$ as $\mathrm{C} 4$ is considered to be damaged as a result of a medical condition. For this study, three different scenarios which describe the common motion condition of the head-neck system are modelled. The first one refers to the effect of the head weight over the considered section. In the second case the average patient weight is supported by $\mathrm{C} 3$ and $\mathrm{C} 5$ vertebrae. The last case simulates extreme loading conditions as vertebrae lesions occur when these are compressed beyond its failure limit; the ultimate stress to compression load failure value is applied to C3. The stability and mechanical behaviour of cervical plates under compression loading conditions is evaluated using the Finite Element Method (FEM). Cervical plates are useful to restore stability of the spine by improving the inter-vertebral fusion, particularly when the cervical body has been damaged. The results show that the stresses on the plate and fixation screws, for the three cases, are within the elastic range. Conversely, it has to be considered that cortical and trabecular bone densities vary from one patient to another due to a number of factors, which can influence the fixation conditions of the screws. In the case of this analysis, healthy bone conditions were considered and the obtained results show that the risk of the integrity of the screwimplant-vertebrae system is not compromised.
\end{abstract}

\section{Introduction}

Several reports [1] mention a diversity of cervical spine pathologies, some of which are not of recent knowledge. For example, the Egyptians knew 4500 years ago about paraplegias due to cervical lesions [2]. Bohler [3] was the first to use an anterior plate and fixing screws to stabilize vertebral bodies to their original position, these plates were used only in trauma cases. However, new technologies and designs have been used to replace the damaged vertebral discs in cervical discectomy procedures. Surgical techniques provide cervical stability, allowing the patients to return to their daily activities after a short recovery time [4]. In all these cases, it is important to evaluate the structural integrity of all the involved elements. The performance of a bone graft was previously analyzed in [9]. Here it refers to the stabilization of a cervical unit (C3-C5) in conjunction with a cervical plate under compression conditions. The numerical results show that resultant stresses in the bone graft are within an acceptable range for lateral displacements, as they produce a displacement below $3 \mathrm{~mm}$. Thus, indicating that the arrangement is stable. From the 
clinical point of view, this surgical technique simplified the procedure that was commonly used as no wires are used. However, it is necessary to analyze the structural integrity of the system, as stresses between the screws and vertebrae could produce a loosing of the fixation.

\section{Problem statement}

The human spine (Fig. 1) is the main distribution channel of the central nervous system. Its mechanical integrity not only influences the stability of the body, as the loads are effectively transferred through it, but when compromised the effect on a patient can range from an ache to a severe disability. The interface between the skull and the thorax is known as the cervical spine (Fig. 2) and it is composed by 7 vertebrae ( $\mathrm{C} 1$ to $\mathrm{C} 7)$. $\mathrm{C} 1$ is called Atlas, which acts as the base of the skull, $\mathrm{C} 2$ allows the movement of the neck system, and it is referred to as the axis. Vertebrae $\mathrm{C} 3$ to C6 serve as sustain of the neck, transferring load from the skull to the thoracic vertebrae T1.

A cervical injury takes place when one of the cervical vertebrae is subject to compression beyond the stress limit of the vertebra, which for analysis purposes is considered as a composite material due to the mechanical properties of cortical and trabecular bone. In order to treat cervical lesions surgical procedures have been developed. In this sense, Corporectomy is one of the most useful methods in orthopaedic surgery to treat extreme lordosys, which can be the result of a trauma or degenerative processes due to aging, or associated to a disease such as tumours or infections. This surgical technique, which uses a replacement of a bone graft between two intact adjacent vertebrae, offers the possibility to incorporate the patient to their normal activities almost immediately. To complement this procedure a cervical plate is used to fix the bone graft and the vertebrae, guarantying the mechanical stability of the elements in the system.

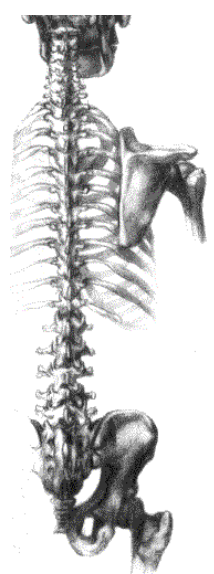

Fig. 1 Human Spine.

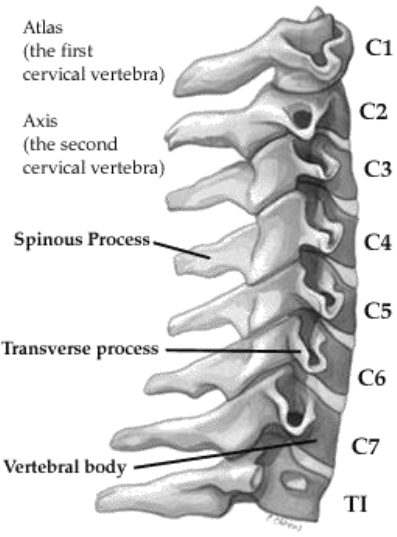

Fig. 2 Cervical Spine.

The analysis of this work is focused on the evaluation of a cervical plate OrtoSintese 4774/08 (55 $\mathrm{mm}$ ) installed in the $\mathrm{C} 3-\mathrm{C} 5$ range of a patient, whose $\mathrm{C} 4$ vertebra is replaced using a bone graft taken from the iliac crest. The plate is attached to the anterior surface of the spinal column, stabilizing and compressing the vertebrae surrounding the bone graft. The Finite Element Method was used for this analysis.

\section{Materials and Methods}

The cervical plate used on this work (Fig. 3) is made of a Titanium alloy Ti-6A1-4V, with the following mechanical properties provided by the manufacturer: $E=102 G P a, v=0.30, S y=827$ MPa. 


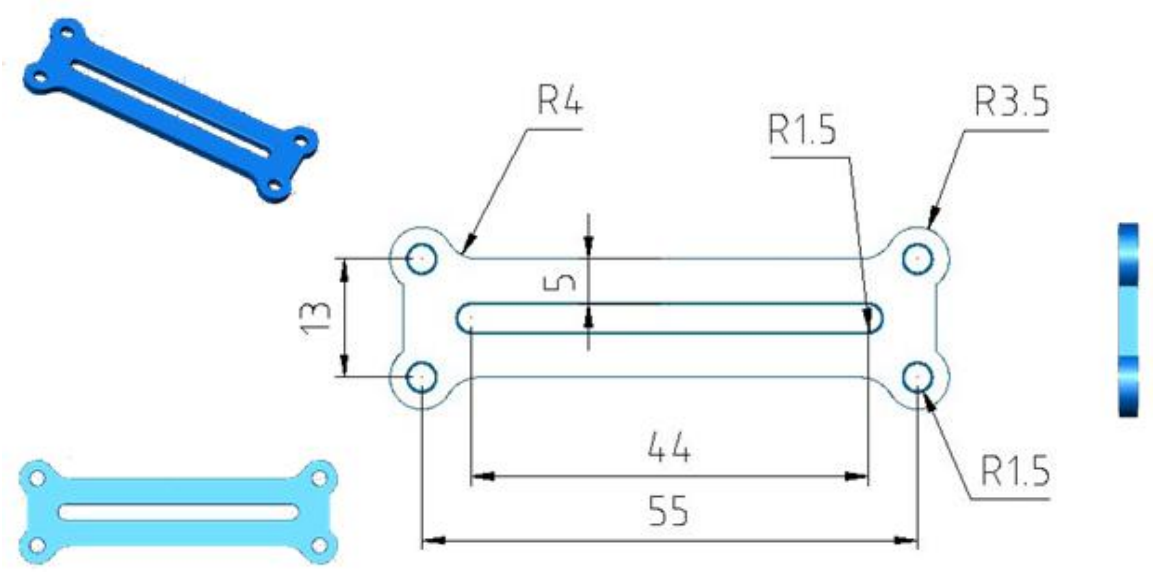

Fig. 3 Geometry of Cervical Spine Plate (Dimensions in $\mathrm{mm}$.)

To obtain an accurate model of the system, the cervical plate must be bended to get a curvature of $35^{\circ}$, accordingly with the natural form of the spine (lordosys). Fig. 4 shows the CAD model of the cervical vertebra C3-C5 with the necessary curvature, in which the cervical plate must be fixed. Fig. 5 shows the final geometry for this plate.

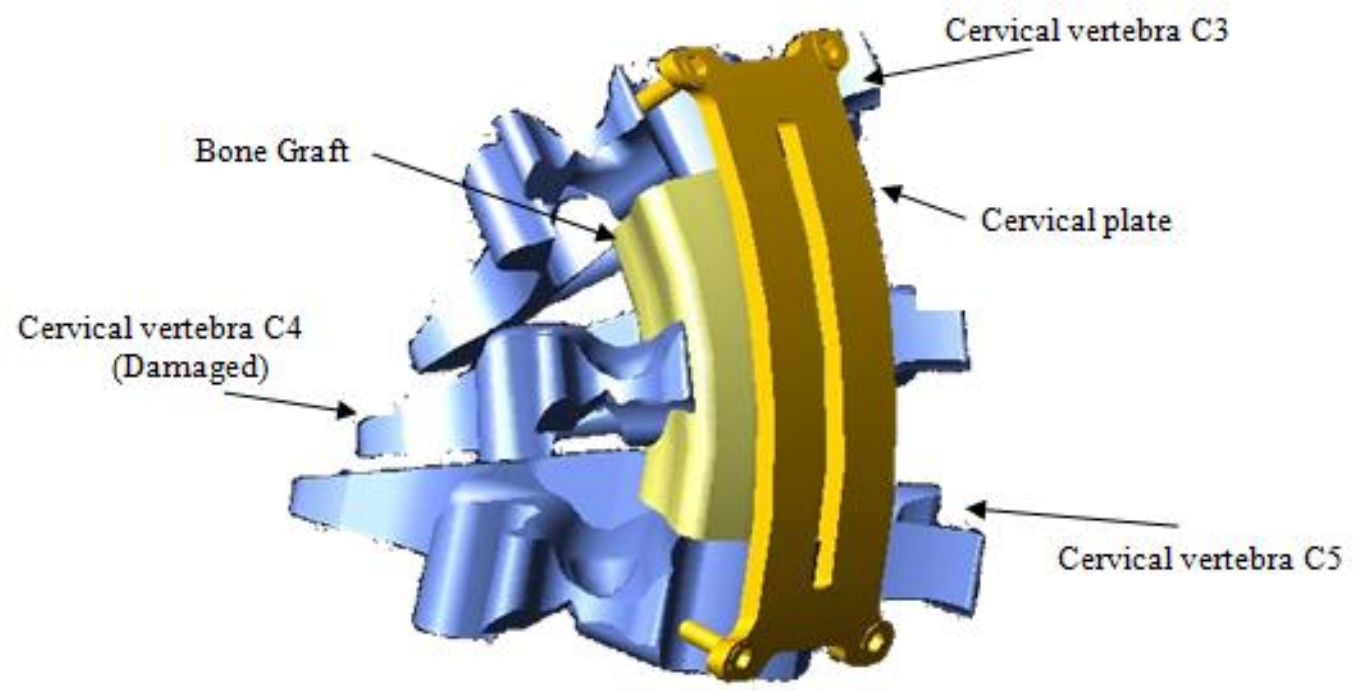

Fig. 4 CAD model of the Cervical vertebrae C3- C5

In accordance to the cervical plate manufacturer and technical information, this bend does not affect the mechanical properties of the plate. The main purpose of the shape in the design of the plate is to reduce the distance between the screws fixed to the upper and lower bone to the adjacent vertebrae through the plate, thereby allowing the device to properly respond to changes on the loading conditions. The lateral flexion of this intermediate portion does not allow the device to protrude anteriorly into critical organs or posteriorly into the graft. 


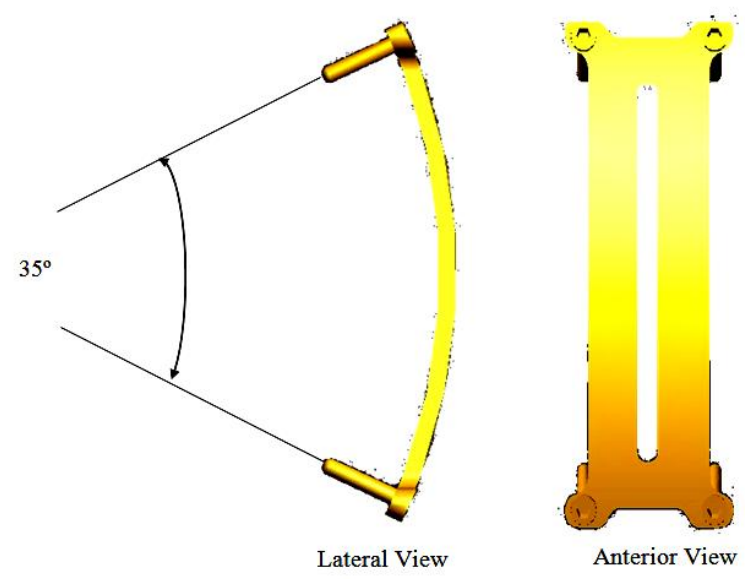

Fig. 5 Final geometry for the cervical plate, including fixing screws.

The FEM model of the system, in which the cervical plate is fixed to the vertebrae, is illustrated in Figure 6. As the phenomenon to study is the load transfer between the vertebrae adjacent to the damaged one, the vertebrae used for the simulation were $\mathrm{C} 3, \mathrm{C} 4$ and $\mathrm{C} 5$, taking $\mathrm{C} 4$ as the damaged vertebra. It is also considered that $\mathrm{C} 4$ is replaced by a bone graft with the same mechanical properties used in the rest of the vertebrae and being adjacent to the superior and inferior surfaces of C3 and C5 respectively [9]. The range of compression strength of the bone graft is: $5-15 \mathrm{MPa}$. [6]

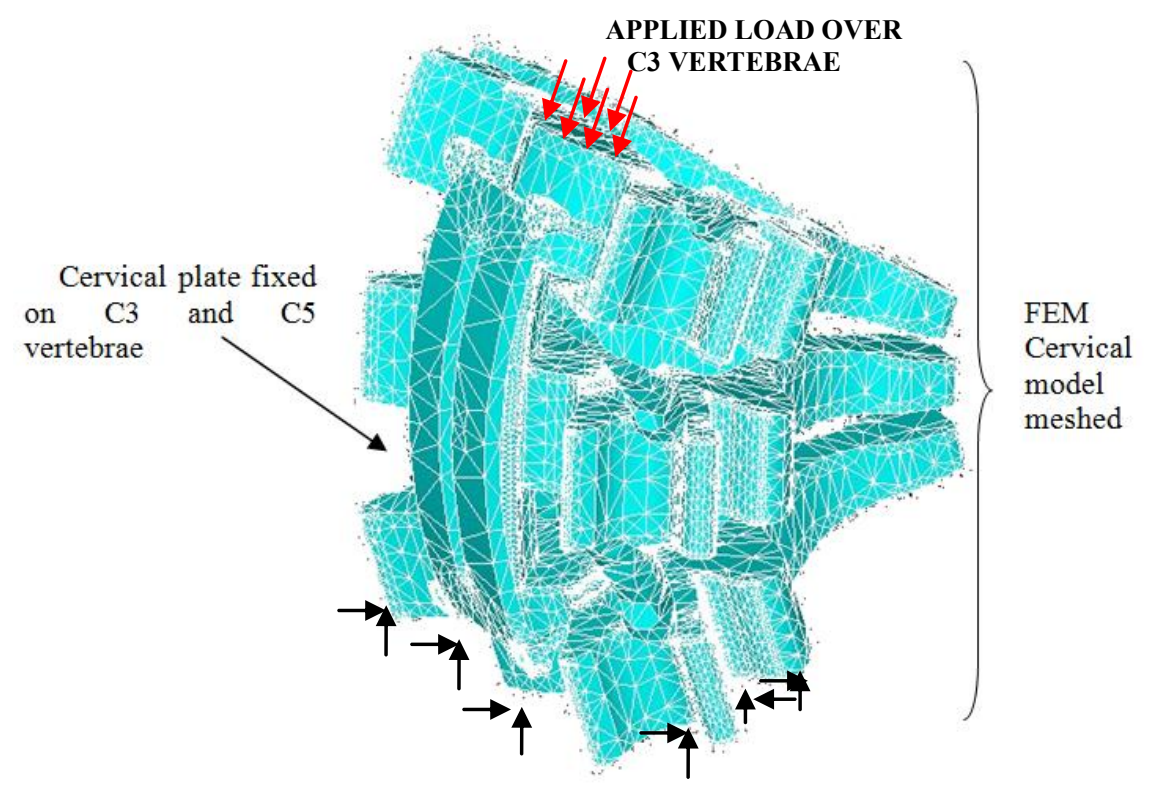

FIXATION ON THE BASE OF C5 VERTEBRAE AS BOUNDARY CONDITIONS

Fig. 6 Boundary and Loading Conditions of the Finite Element Cervical model.

\section{Analyzed models}

The finite element model (FEM) used in this study was previously validated numerically and experimentally as detailed in [5]. The experimental validation consisted in applying a compression load on a system composed by cervical vertebrae of a porcine specimen, as the mechanical properties are similar to that of the human vertebra, the referred plate and fixation screws. Even though the 3-D model does not consider the thread geometry of the screws, the CAD software used to model these elements (Mechanical Desktop) allows applying mechanical properties to the cylinder so it can represent the fixation properties of a screw, considering the type of thread, pitch, and number of threads. Furthermore, in the Finite Element Model the coincident nodes allow to apply the correct boundary conditions between vertebral body and the titanium screws. 
The porcine C4 in [5] was replaced with a bone graft. Upon the validation of the FEM model, the cases analysed in this study were discussed with the medical team. Summarizing, the FEM mesh consists of 95782 elements and 157633 nodes. The results considering the loads, boundary conditions and FEM was solved with ANSYS.

In order to accurately simulate the load transfer between the vertebrae and the plate, it is highly important that the nodes, where the load is applied and transferred, coincide with each other. To this end, it has to be taken into consideration the way that the system works. The load is transferred from $\mathrm{C} 3$ to $\mathrm{C} 5$ through the cervical plate, in a $60 \%$ ratio, whilst the bone graft supports the remaining $40 \%$. This criterion was established by DiAngelo and Foley on the analysis of fracture mechanism on cervical specimens [8]. To model this behaviour of the system in the finite element model, the following considerations are made: The load between C3 and the plate is transferred through the fixation screws, being necessary that the nodes between these two elements coincide to simulate a proper load transfer. Following this line of thought, the load between the plate and C5 is also transferred through the fixation screws. Finally, to model the load transfer between the vertebrae, C3 and C5, and the bone graft, the nodes of the interior surface of C3, and the nodes of the superior surface of $\mathrm{C} 5$, must coincide with the respective surface nodes of the bone graft. It is important to point out that there are not coincident nodes among the plate, the vertebra and the bone graft, as if there were to be coincident nodes, the boundary conditions would not represent accurately the interaction of the elements of the system.

\section{CASE 1 Weight Head over FEM Model}

The compressive load used to account for the weight of the head was $38 \mathrm{~N}$, which represent $6.9 \%$ of the body weight, and it was applied perpendicularly to the superior surface of $\mathrm{C} 3[6,7]$.

\section{CASE 2 Average patient weight over FEM Model}

In this case, the average weight of a patient $(637.5 \mathrm{~N})$ is used as the compressive load, applied perpendicularly to the superior surface of the cervical model [6]

\section{CASE 3 Compression load failure of a cervical vertebra over FEM Model}

Since the mechanism of any given trauma that led to a vertebra failure involves that it was subjected to a compressive load beyond its ultimate stress value, this case considers a compression load of $6376.5 \mathrm{~N}$ as the compression load failure of the vertebra [8]. To model these loading conditions acting on the neck system, the compressive load, as in the previous cases, were applied perpendicularly to the superior surface of the cervical model.

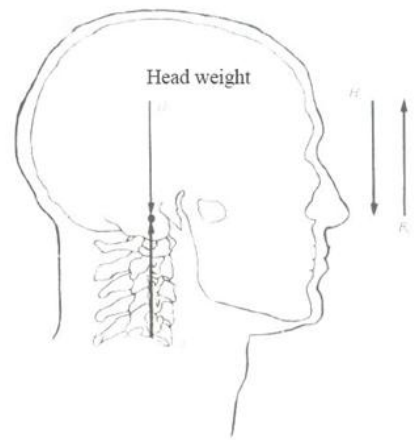

Case 1

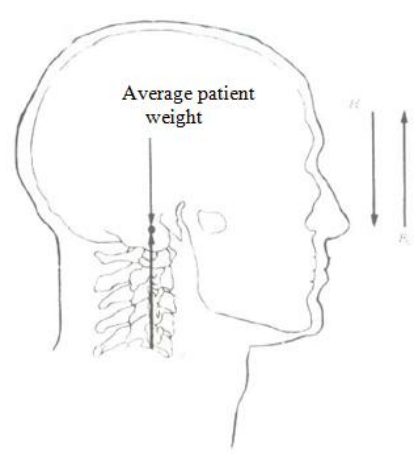

Case 2

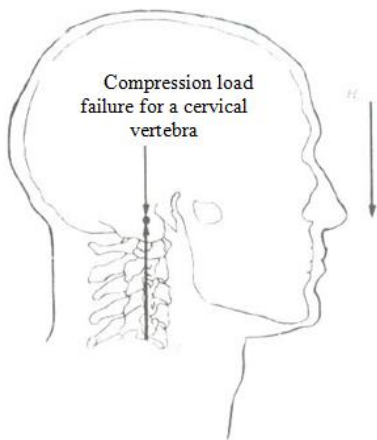

Case 3

Fig. 7 Compression loading for the three study cases.

In Fig. 7 the loading conditions of the system are illustrated. It is in accordance with the parametric and boundary conditions. $\mathrm{C} 5$ is the vertebra considered as the base element for which diverse nodes at the inferior surface are fixed as boundary conditions. Besides, the model is refined in zones where it is expected some severe stress gradients. 


\section{Results}

\section{CASE 1 Weight Head over FEM Model}

The Von Mises stresses obtained in the FEM, in the compressive loading case 1 (Fig. 8), shows that a stress of $70.26 \mathrm{~Pa}$ is produced in the centre of the plate by the sole load of the head's weight, while around the screw holes the stress reaches a magnitude of 316.2Pa. In all cases, the values are below the elastic limit of the Titanium alloy Ti-6A1-4V, which is $S y=827 \mathrm{MPa}$.

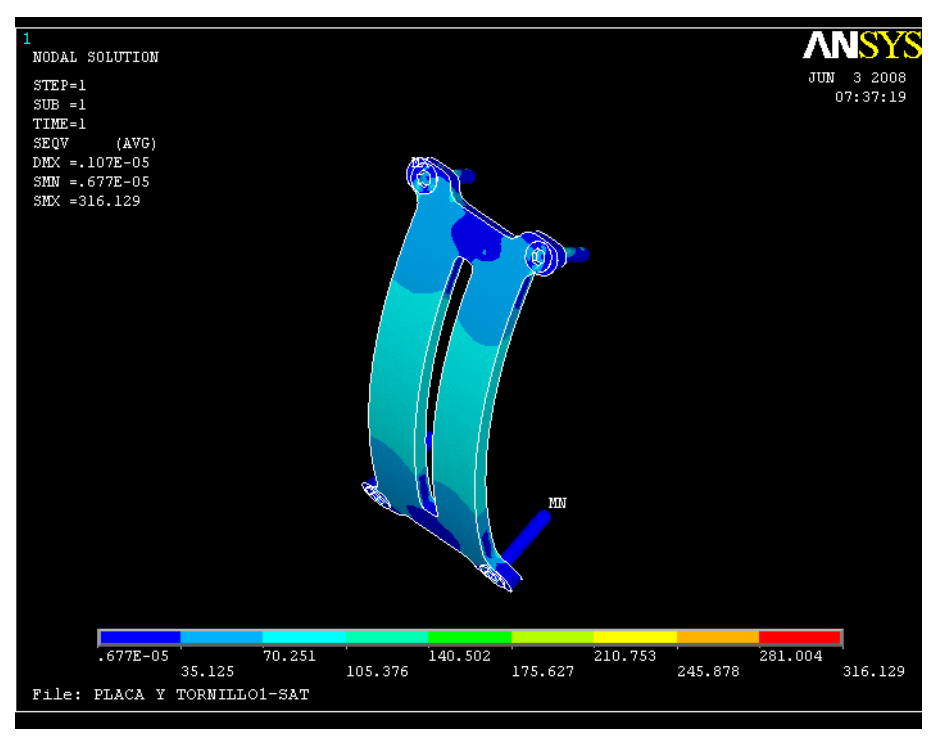

Fig. 8 Von Mises Stress distribution results for the case $1(\mathrm{~Pa})$.

\section{CASE 2 Average patient weight over FEM Model}

For this case, the Von Mises stresses show that a stress of $662.83 \mathrm{~Pa}$ took place at the centre of the plate, while around the screw holes, 3351.72Pa was obtained.

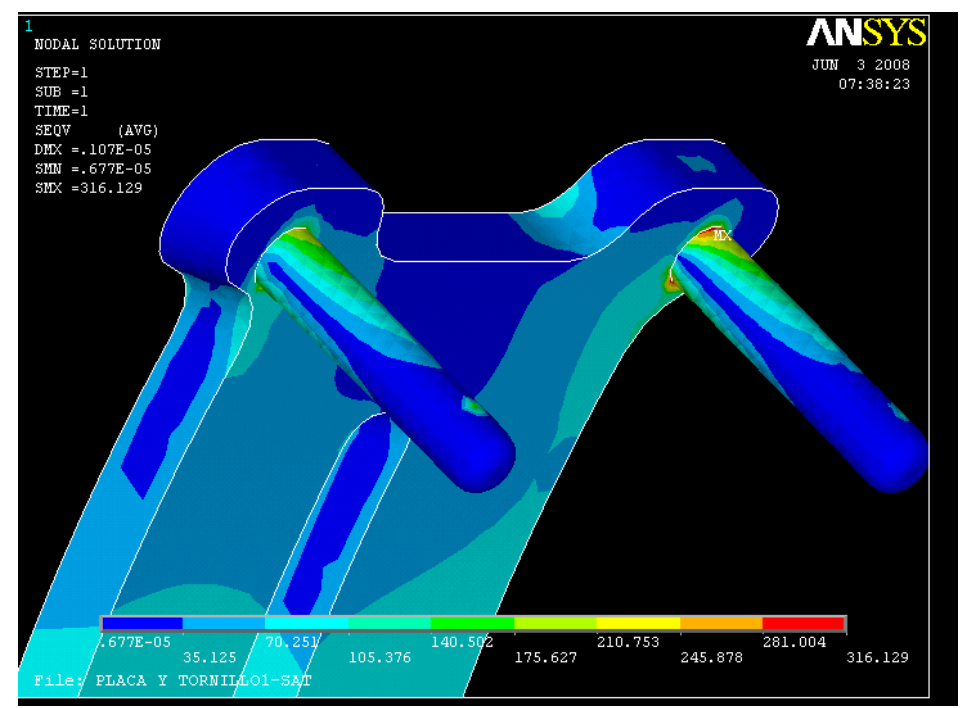

Fig. 9 Von Mises Stress distribution results for the case 2 (MPa). 


\section{CASE 3 Compression load failure of a cervical vertebra over FEM Model}

The Von Mises stress obtained is $7.025 \mathrm{MPa}$ at the centre of the plate, while around the screw holes; the stress reaches a magnitude of $328.2 \mathrm{MPa}$. For this extreme case, this stress value is still around $40 \%$ below the elastic limit of the Titanium alloy.

\section{Conclusions}

The system formed by the cervical vertebrae C3 and C5, the bone graft and the cervical plate were modelled and analyzed using the Finite Element Method. Given the importance of these implants to restore stability in the cervical spine, improving the fusion of the vertebral bodies after a surgery of spine, a FEM parametric modelling allows the simulation of several loading conditions, suggested by the medical counterpart, to evaluate the behaviour of the system under possible operational conditions, where the maximum stress levels, acting on the components, can be identified. These results confirm that the Titanium alloy plate used, in conjunction with the fixation method, operates safely under the elastic limit of the material, even for the most extreme loading condition simulated for case 3 .

The results for case 1 represent the behaviour of the implants when the patient is at a recovery stage, where the movement of the neck system is limited by the use of a Philadelphia neck support. The results for case 2 can be related with the daily activities of a patient that has resumed its usual routine. Case 3 evaluates the stress conditions under which the system is subjected in the event of a possible accident, that implies a sudden movement of the head, either by a fall or a car accident. In all cases, the Von Mises stress showed that the elements work on the elastic range of the material, which represents an appropriate mechanical behaviour guarantying the stability and integrity of the system.

Finally, it can be said that human motion can be affected when any of the vertebrae of the Spine is damaged as a consequence of any trauma previously described. In this sense, FEM models can simulate diverse loading conditions, allowing the virtual evaluation of any component of the human structure, whether or not orthopaedic implants or prosthesis are considered in the model. Such evaluations are usually impossible to verify in-situ on a patient. The virtual modelling of biomechanical systems can help medics in the evaluation of each case. This study considered the cervical geometry of an average Mexican patient, and the possibility of changing the parametric properties of the model for other study cases for different loading conditions in accordance to the great number of possible movements that the neck and the skull can reproduce.

\section{ACKNOWLEDGMENTS}

The authors thank the National Council for Science and Technology, CONACYT, Mexico; the National Polytechnic Institute, IPN, Hospital General La Villa and ISSSTE Hospital $1^{\circ}$ de Octubre; for the means and facilities for the development of this research. Project No. SEP/CONACYT 47728, SEP/CONACYT 2005-49701, (IPN) SIP20071298, (IPN) SIP20060497, (IPN) SIP20050827, CONACYT Grant 152947.

\section{References}

[1] K. Rojas, Analysis and design of anterior cervical plates using the Finite Element Method, International Congress on Computational Bioengineering, Spain, (2003), p.304-310. 
[2] J. Breasted. "The Edwin Smith Surgical Papyrus", University of Chicago Press, Chicago, (1930), Case 2, Vol. I, p.431

[3] J. Bohler, "Anterior plate stabilization for fracture - dislocations of the lower cervical Spine", J Trauma 20(3):203-5. (1980).

[4] A. Krivoy, "Estabilización cervical posterior con placas de Roy - Camilla". Reporte de un caso, Centro Médico, 39:141, (1993).

[5] J. Beltrán-Fernández, L. Hernández-Gómez, G. Urriolagoitia-Calderón, G. Rodríguez-Cañizo, M. Dufoo-Olvera y A. González-Rebatú, "Comportamiento mecánico estructural de un injerto óseo en una unidad de carga para la sección cervical C3-C5 bajo la acción de cargas de compresión, empleando el Método del Elemento Finito", XV International Materials Research Congress 2006, symposium 14 Mecánica de Fractura, Academia Mexicana de Ciencia de Materiales, Cancún, Quintana Roo, México, 20- 24 Agosto. (2006)

[6] J. Beltrán-Fernández, L. Hernández-Gómez, G. Urriolagoitia-Calderón, G. Rodríguez-Cañizo, M. Dufoo-Olvera y A. González-Rebatú, "Distribución de esfuerzos por la acción de cargas de compresión en la vértebra cervical C5, empleando el Método del Elemento Finito" Científica, Vol. 9, núm. 3, Julio-Septiembre del 2005, ISSN 1665-0654, p.135-142.

[7] B. Le Veau: Biomecánica del movimiento humano, Trillas Ed. (1991)

[8] D. J. DiAngelo and K. T. Foley. An improved biomechanical testing protocol for evaluating spinal arthroplasty and motion preservation devices in a multilevel human cadaveric cervical model Neurosurg Focus 17 (3):E4, (Memphis, Tennessee), (2004).

[9] J. Beltrán-Fernández, L. Hernández-Gómez, G. Urriolagoitia-Calderón, G. Rodríguez-Cañizo, M. Dufoo-Olvera y A. González-Rebatú, G. Urriolagoitia-Sosa. "Mechanical Behavior of a Calcium Phosphate Ceramic Bone Graft used in the Rehabilitation of a C4 Human Vertebra", Transtech "Applied Mechanics and Materials". 5th BSSM International Conference on Advances in Experimental Mechanics, University of Manchester, (United Kingdom), 4-6 September, (2007).

[10] R. Rodríguez-Cañizo, L. Hernández-Gómez, J. Beltrán-Fernández, G. Urriolagoitia-Calderón, M. Dufoo-Olvera, Análisis biomecánico de un disco intervertebral porcino lesionado - estudio experimental, $8^{\circ}$ CONGRESO IBEROAMERICANO DE INGENIERÍA MECÁNICA, (Cusco, Perú), 23 al 25 de Octubre, (2007). 